\title{
Introduction to Anti-Money Laundering Regulation and Compliance
}

\section{A Overview}

Three major themes run throughout this book. First, it provides a framework for understanding the risk-based approach (RBA) of AML/ CFT regulation. RBA pervades four levels of the regulatory hierarchy: standard-setting at the international level by the Financial Action Task Force (FATF); the statutory and regulatory framework at the national level; sector-specific supervision at the sectoral level; and covered firms' compliance at the ground level. A basic grasp of RBA's fundamentals is essential for effectively designing, implementing, and remediating AML/CFT compliance systems. For this reason, the book devotes a separate chapter each to corporate governance and risk management fundamentals.

Second, a law enforcement objective strongly conditions AML/CFT compliance program obligations and regulatory expectations. Law enforcement authorities (LEAs) expect that SARs will provide leads for criminal investigations and prosecutions of $\mathrm{ML} / \mathrm{FT}$ and the underlying predicate crimes. However, covered firms' ${ }^{1}$ primary supervisors have regulatory expectations that diverge from the law enforcement objective in important respects, making compliance at times problematic in satisfying BSA and sanctions requirements due to conflicting compliance expectations.

Following BSA terminology, this book employs the term 'covered' to identify sectors and firms that are subject to AML/CFT regulation even if of limited scope. 
Third, the book examines the various factors which may compromise a firm's AML/CFT compliance and risk management systems and undermine the firm's ability to manage ML and FT compliance risk ${ }^{2}$ effectively. Taken together, these factors create the 'compliance paradox' of AML/ CFT regulation. One factor involves the tension between covered firms' business models for revenue-generation and their compliance obligations. The revenue-generating strategies of financial institutions (FIs) create incentive structures at sharp variance with AML/CFT obligations, more so than in many other areas of financial regulation.

Another factor contributing to the paradox is the external nature of the BSA and sanctions regulatory regime which arises from its law enforcement objective. Covered firms do not create the social costs that the regulation is designed to mitigate. This 'externality' factor can limit a firm's employees' active acceptance of, and engagement with, their compliance obligations. Still another factor is the cost structure of the AML/CFT compliance and risk management systems that can lead firms to curtail expenditures necessary to align internal controls with business expansion strategies.

As I prepared to submit the book for publication, Congress passed the Anti-Money Laundering Act of $2020^{3}$ (AML Act) in January 2021. The AML Act is arguably the most comprehensive reform of AML/CFT regulation since the Bank Secrecy Act was first enacted in 1970. The AML Act will modernize and systematize this regulatory regime by eliminating outmoded requirements that have accumulated over the past 50 years. Several of the legislative provisions were foreshadowed in a FinCEN request for comment on the BSA in September 2020. ${ }^{4}$ The AML Act is structured to be evergreen by mandating continuous engagement by a wide range of public and private stakeholders. It creates a highly adaptable framework for FIs that will enable them to detect, prevent, and prosecute future forms of illicit financing during the next several decades. This introduc-

2 For banks, 'compliance risk' is the risk of legal or regulatory sanctions, material financial loss, or loss to reputation a bank may suffer as a result of its failure to comply with laws, regulations, rules, related SRO standards, and codes of conduct. BCBS, 'Compliance and the compliance function in banks' 7 (April 2005).

Public Law No. 116-283, $\$ \$ 6001-6511$.

4 FinCEN, 'Anti-Money Laundering Effectiveness', 85 FR 58023 (17 September 2020) [FinCEN comment request]. 
tion will close with a brief assessment of the expected impact of the AML Act in reducing AML/CFT compliance cost and compliance risk.

Discussion begins with a description of the book's scope, structure, and intended readership. It then turns to a discussion of the book's key themes and FinCEN's request for comment.

\section{B Book overview}

The book provides a uniquely detailed and comprehensive guide to the compliance programs, risk management systems, and reporting and recordkeeping required by BSA and OFAC law and regulation. It is designed as a reference tool for negotiating the complex web of mandatory BSA and sanctions compliance policies and procedures and internal risk controls.

Book's scope, structure, and intended readership

The book comprehensively covers all significant BSA reporting, recordkeeping, and compliance program requirements and OFAC sanctions provisions. To help cement readers' understanding, the book includes numerous boxes, set off from the main text, highlighting relevant enforcement actions, regulatory expectations, and compliance practices. Given the increasing importance of technology in BSA and sanctions compliance, the book pays special attention to risk management practices involving machine learning in particular and RegTech more broadly.

Following the risk-based approach, the book groups firms into three tiers according to their level of BSA compliance obligations. The book's primary focus is on banks and capital markets firms, ${ }^{5}$ which it classifies as 'Tier 1' sectors. These firms are of the most concern to AML/CFT policymakers and regulators due to the direct and immediate access to the global financial system which they provide to their customers. They are thus subject to the most rigorous requirements. Tier 2 firms comprise casinos and card clubs, money service businesses (MSBs), life

These comprise depository institutions, securities broker-dealers, mutual fund companies, futures commission merchants, and introducing brokers in commodities. In this book the term 'bank' refers to all types of regulated depository institutions that are covered by the BSA. 
insurance companies, and several other sectors. ${ }^{6}$ Gatekeepers, which include lawyers and accountants, among others, fall into Tier 3. By and large, AML/CFT law does not apply to Tier 3 persons other than limited transactional reporting obligations. Tier 3 persons nevertheless present significant ML and FT vulnerabilities, thus reflecting a significant regulatory compliance gap.

'Know your customer' (KYC) provides the foundation for AML/CFT compliance programs. The government has underscored the importance of KYC by progressively enhancing the KYC framework. In 2016, FinCEN added the beneficial ownership (BO) and customer due diligence (CDD) rules, which, require, respectively, Tier 1 firms to identify and verify a legal entity's individual owners and establish customer risk profiles as a benchmark for suspicious transaction monitoring (TM) and sanctions alerts.

The book is written for AML/CFT compliance practitioners and risk managers, seasoned and beginning alike, and students of the subject in law and certificate programs. Practitioners of Tier 1 firms considering entering into arrangements with Tier 2 or Tier 3 firms or individuals as third parties will find the book useful as a reference guide to BSA/ OFAC obligations in their due diligence review of these counterparties. Moreover, practitioners responsible for any covered firm should find the footnoted references helpful in their work for clients. To this end, the Appendix lists relevant sources on all covered sectors and Tier 3 sectors.

\section{$2 \quad$ Chapter-by-chapter overview}

The book's sequence of chapters, illustrated in Figure 1.1, enables readers to progressively build upon their knowledge with increasing understanding of prescriptive and risk-based compliance requirements by the time they reach Chapter 5, which details compliance programs requirements, and Chapter 8, which covers transaction monitoring (TM) and sanctions screening. Risk-based requirements become progressively more important.

These include credit card systems operators, nonbank residential mortgage lenders, dealers in precious metals, stones, or jewels, and housing GSEs. 


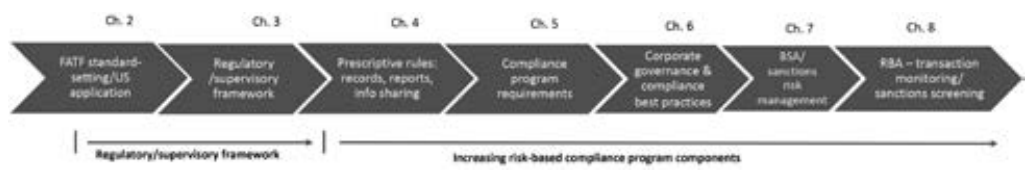

Figure 1.1 Chapter/subject sequence

Chapter 2 defines money laundering and terrorist financing, describes the FATF's international standard-setting process, FATF's methodology for assessing ML and FT risks and its application to the US, and discusses the US's unique ML and FT threats and vulnerabilities. The most significant vulnerability is the US's status as the world's reserve currency. Chapter 3 covers the BSA/OFAC regulatory and supervisory structure, agency jurisdiction over the covered sectors, enforcement authority, and enterprise and individual liability for BSA and sanctions violations. Chapter 4 covers the prescriptive requirements for reporting, recordkeeping, and information sharing. Chapter 5 details the BSA's five compliance program pillar requirements, which include $\mathrm{CDD}$ as the fifth and most recently added pillar, customer identification programs (CIPs), and foreign correspondent and private bank accounts.

Chapter 6 provides an overview of corporate governance and the BSA and sanctions compliance function. It also describes boards' decision-making process in allocating corporate resources for revenue generating strategies versus funding compliance in order to maximize shareholder returns, the primary objective of US corporations, the skewing of this calculus by the compliance paradox, and prosecutorial guidance for 'effective' compliance programs. Chapter 7 describes the basic elements of BSA and sanctions risk management, including risk appetite and risk assessments, and the three lines of defense (3LOD) model. Chapter 8 covers TM and sanctions screening systems, including $\mathrm{AI} /$ machine learning solutions, New York's Rule 504's TM and sanctions screening program provisions, and model risk and model risk management. Conceptually, Chapter 4 describes the end product, or output, of the compliance programs and monitoring and screening systems of these later chapters. The Appendix provides a list of regulations and official and trade industry guidance on compliance and risk management practices for Tiers 1 and 2 and Tier 3 professionals. 
The book draws on a wide range of practice-oriented and academic sources and primary regulatory materials. Materials include FATF guidance across a wide array of topics and sectoral guidance; the BSA statute; FinCEN, banking agency, SEC and CFTC rule releases and regulatory provisions; FinCEN advisories and OFAC guidance; guidance by the Basel Committee on Banking Supervision; agency examination manuals, the most important being that of the Federal Financial Institutions Examinations Council (FFIEC); FinCEN, DoJ, and primary agency enforcement actions and prosecutions; law firm memos; and white papers of industry associations, certification companies such as ACAMS, and consultants. These fully referenced materials serve the additional purpose of providing sources for students and practitioners who desire to explore a subject of interest in greater detail.

\section{Three themes}

1 The risk-based regulatory hierarchy

The risk-based approach is now deeply rooted in AML/CFT policymaking, regulation, and compliance. The AML/CFT RBA is part of a more general evolution in which Congress and financial regulators have incorporated firms' corporate governance systems' management of risk in both binding regulation and in regulatory and supervisory expectations. At its inception in 1970, AML law initially consisted almost wholly of prescriptive reporting and recordkeeping requirements. AML/CFT compliance is no longer a check-the-box exercise. Reporting is now the output of a complex of interrelated components whose common unifying theme is the risk-based approach. However, prescriptive, rules-based regulation still plays an essential role in providing a uniform floor of compliance obligations for a given tier of covered firms and in creating a database of transactional information for TM and sanctions screening systems.

In the RBA system, the FATF sets up its broad principles ('Recommendations'); legislators implement these principles at the national level to reflect their country's unique ML/FT vulnerabilities; and the primary supervisory agencies further refine risk-based guidance specific to the sectors which they regulate. The individual firms are then required to apply this guidance to their unique risk characteristics in 
implementing their compliance and risk management systems. In theory, the system is designed to ensure that those firms that pose the highest ML/ FT risks are the ones most heavily regulated and supervised.

However, practice does not follow theory as much as would be desired. The US has large regulatory gaps that expose it to significant ML and FT risks. On the regulatory side, opaque legal structures continue to be problematic despite the $2016 \mathrm{BO}$ rule requiring firms to conduct due diligence to verify the identity of the ultimate individual owners and control persons of legal entity customers. In addition, Tier 3 professionals are able to service launderers with little federal or state agency oversight. Despite their Tier 1 level of access to the financial system, investment advisers unaffiliated with a Tier 1 covered conglomerate firm remain generally unregulated.

Furthermore, the US supervisory system has two significant weaknesses that serve to make a risk-based hierarchy imperfect at best. First, the US system of financial supervision suffers from a high degree of fragmentation. Eight separate agencies supervise BSA compliance by banks and capital markets firms. This fragmentation creates two problems. First, each of these primary regulators has a financial regulatory objective that may work at cross purposes with the BSA/OFAC law enforcement objective, as discussed in the next section. Second, certain sectors are left out altogether or are too lightly regulated and supervised in light of their $\mathrm{ML} / \mathrm{FT}$ risk exposure since they do not have a primary federal regulator. ${ }^{7}$

Understanding the primacy of the law enforcement objective helps to elucidate the structural features of AML/CFT regulation. This regime is designed to produce accurate and actionable reports and records for investigating and prosecuting money launderers and terrorist financiers and the criminals who generate the laundered proceeds. However, the law enforcement objective does not fit easily within the existing scheme of traditional financial regulation. Banking agencies' overriding concern is the stability of the financial system and the prudential safe and sound operation of individual banks. Capital markets regulators' primary

Examples of a primary, or 'functional', regulator are the OCC for nationally chartered banks or the SEC for securities broker-dealers. 
concern is fair and transparent business conduct and efficient financial markets. This disconnect creates an inherent weakness in the US system of supervision since the agencies with primary BSA supervisory authority may view - and supervise - BSA compliance through their primary supervisory lens. ${ }^{8}$ sanctions compliance

A combination of covered firms' business models, the external nature of AML/CFT compliance obligations, and the high cost structure of BSA regulation introduces tensions with AML compliance obligations and creates what this book terms a 'compliance paradox'. Such a paradox exists in all areas of financial regulation, but is possibly at its sharpest in AML/CFT and sanctions regulation. Chapter 6 includes a detailed description of the compliance paradox. ${ }^{9}$

Business model-compliance tension

A fundamental theme of this book is the tension between a covered firm's business model with its AML/CFT compliance obligations. This tension is highly correlated with a sector's level of connectedness with the global payments system. Sectors fitting this description largely comprise Tier 1 firms. They typically have a high degree of revenue-generating potential associated with the payments system but also are subject to a high level of regulation. It is precisely this revenue-rich connectedness with the payments system that is the focal point of AML/CFT and sanctions regulation. Boards' duty to maximize enterprise value for their shareholders establishes the tone and dynamic interplay with this tension as well as setting the terms of the compliance paradox.

\footnotetext{
For example, bank regulators' primary concern is banks' prudential operation rather than the functional utility of SARs for FBI investigations. In fact, without exception, federal banking agency enforcement actions frame ML/FT wrongdoing in prudential safety and soundness terms concerning the depository institution's financial wellbeing. Only in a few cases have fines for BSA and sanctions violations raised questions of a covered firm's financial viability. See Table 6.1, Chapter 6, section C.2.i. Nevertheless, capital markets agencies 'expertise as business conduct regulators does dovetail to a certain extent with the BSA/OFAC law enforcement objective.

9 See Chapter 6, section C.
} 
On the one hand, providing financial services to customers and counterparties is a core means by which FIs generate revenue. For banks, deposit-taking and other payment services are key to their funding and business strategies. For broker-dealers, conducting agency and principal transactions is a primary means of earning commission-based compensation and market-making profit. On the other hand, BSA and sanctions law requires a firm's employees to monitor customer activities, in some cases to report them to the government, and even potentially to reject an opportunity to provide profitable services to certain customers with questionable backgrounds. In a word, AML/CFT requirements in several ways interfere directly with these covered firms' business models of revenue-generation.

This tension plays out in a highly tangible manner at the transactional level, heightening risk of violation of BSA and sanctions law by employees incentivized by transaction-based compensation. In several enforcement actions, employees and their managers have intentionally stripped identifying information from international funds wire transfers in an effort to foil criminal investigators.

\section{ii Externality of BSA and sanctions regulation}

Unlike other regulatory regimes designed to compel covered firms to internalize the negative externalities that their businesses impose on society and the economy, ${ }^{10}$ BSA and sanctions law combats serious criminal activities, such as drug smuggling, that generally do not result from these firms' business activities. In contrast, bank regulation, among other things, requires banks to carry additional capital to safeguard them from insolvency and taxpayer loss on insured deposits. Unlike AML/CFT regulation, the latter requirement can also enhance the banks' franchise value.

BSA and sanctions law requires firms to put on an investigative hat, seek detailed information from prospective customers, and report their suspicious activities to the government. Some critics of AML regulation characterize such compliance obligations as 'deputizing' bank officers and securities brokers as law enforcement agents. The overriding and sole objective of AML/CFT regulation is to provide useful information to the

\footnotetext{
10 A prime example is environmental regulation that requires a steel mill to install anti-pollution devices to prevent pollution of the environment caused by its manufacturing activity.
} 
government that will enable it to investigate and prosecute the underlying predicate crimes in addition to the associated ML and FT. ${ }^{11}$ In addition, a separate regulatory regime that is typically integrated into a AML/CFT regime is the requirement to comply with sanctions administered by OFAC. Like the former, this requires constant vigilance for each new and existing account or commercial transaction.

iii

\section{High costs of BSA and sanctions compliance}

A third factor contributing to the compliance paradox is the high level of expenditure required to establish and implement a 'reasonably designed' BSA and sanctions compliance system that will meet regulatory expectations. AML/CFT regulation imposes one of the costliest compliance regimes of all areas of financial regulation. ${ }^{12}$ It is estimated that financial services firms spend $\$ 25$ billion annually for AML/CFT compliance. ${ }^{13}$ The costs of this regulatory regime arise from a number of factors. The government's core concern - timely, accurate, and actionable suspicious activity reports - requires the larger banks to design and implement a compliance and risk management infrastructure involving sophisticated alert systems managed by experienced specialists with expertise in modeling and model risk management, and hire a large staff of alert management professionals. Moreover, BSA compliance has a high variable cost component since a large portion of the infrastructure must be replicated in tandem with expansion of business.

iv

\section{Systemic compliance deficiencies due to compliance paradox}

These three factors can motivate a board of directors to underfund and otherwise compromise their compliance and risk management systems, causing business initiatives to outpace risk management and compliance capacity. This is a finding common in many BSA and sanctions prosecu-

11 To greatly simplify, AML/CFT regulation imposes three basic requirements: obtaining, maintaining, and transmitting relevant information to law enforcement. Ian Carrington and Heba Shams, 'Elements of an effective AML/CFT framework: legal, regulatory, and best institutional practices to prevent threats to financial stability and integrity' (2006) 1, Seminar on Current Developments in Monetary and Financial Law Washington, D.C. (23-27 October 2006).

12 According to one leading consulting firm, AML/CFT staffing has increased an estimated tenfold in the five years prior to 2017. 'The new frontier in anti-money laundering', McKinsey \& Company (2017).

13 '2018 true costs of compliance', LexisNexis Risk Solutions (2018). 
tions. At the extreme, bank officers collude with launderers and sanctions targets to evade detection, with boards and senior management made complicit by their willful blindness. More broadly, this book hypothesizes that these factors go far in explaining the systemic compliance deficiencies found in prosecutions of banking firms over the last decade.

\section{Anti-Money Laundering Act of 2020 and FinCEN comment request}

Both the AML Act and FinCEN comment request are expected to reduce compliance costs and compliance risk for banks, capital markets firms, and other FIs governed by BSA compliance program requirements. The AML Act seeks to accomplish this objective in four major respects. First, it will shift the compliance customer due diligence obligation to identify and verify beneficial owners of legal entity customers to the newly formed shell companies that these owners establish, with a grace period for existing companies. Although covered firms will still be required to establish and enforce policies and procedures reasonably designed to identify and verify beneficial owners, it is expected they will fulfill this obligation through access to a central beneficial ownership registry established and operated by FinCEN. ${ }^{14}$ Second, it will create an infrastructure for sharing confidential information and coordinating compliance best practices between regulators, FIs, LEAs, and between the firms themselves. A consensus has emerged among policymakers that information sharing and coordination between the public and private sectors will result in a more efficient and less costly AML/CFT regime while also promoting the law enforcement objective. Among other things, the AML Act creates a 'FinCEN Exchange' to facilitate voluntary public-private information sharing among LEAs, national security agencies, FIs, and FinCEN to promote innovation and technical advances in reporting. ${ }^{15}$

Third, in several of its provisions the AML Act seeks to establish consistent and uniform compliance expectations, which will reduce the compliance risk arising from the US's fragmented supervisory structure and its conflicting regulatory objectives. Banking agencies' top priority is

\footnotetext{
14 AML Act, Title LXIV.

15 Ibid. $\$ 6103$.
} 
banks' prudential safe and sound operation, while that of FinCEN and the LEAs is to investigate and prosecute money laundering and its underlying criminal enterprises and to disrupt terrorist financing and terrorist acts. To this end, among other things, the AML Act establishes a framework for instructing primary federal regulators and state agencies on FinCEN's national strategic priorities. ${ }^{16}$ Fourth, the legislation promises to reduce compliance risk and compliance cost by modernizing the AML/CFT regulatory framework. For example, the AML Act directs the Treasury Secretary to establish streamlined SARs that permit filing of noncomplex information while not diminishing their law enforcement usefulness. ${ }^{17}$

The FinCEN comment request's rulemaking would dovetail with several of the AML Act's major policy initiatives. Three areas of focus are noteworthy. First, the request proposes that AML/CFT compliance programs incorporate national strategic priorities. ${ }^{18}$ Second, future regulation would make firms' programs more flexible and adaptable in addressing 'evolving threats of illicit finance' by further enhancing the risk-based approach. Risk assessments would become mandatory. ${ }^{19}$ Firms would more efficiently allocate internal resources to high-risk areas, guided by national strategic priorities. ${ }^{20}$ Finally, the FinCEN request would help to promote enforcement priorities by systematically applying AML/CFT regulation across industry sectors subject to the BSA. For the first time, rules would define an 'effective and reasonably designed' compliance program and apply it to all FIs currently subject to compliance program rules. ${ }^{21}$

\footnotetext{
Ibid. $\$ 6101$.

Ibid. $\$ 6202$.

18 An explicit definition might also ensure that primary regulators' supervisory expectations are in greater accord with those of FinCEN in achieving the law enforcement objective. FinCEN comment request 58026 (such definition would seek to 'implement a common understanding' between supervisory agencies and their regulated firms). This would address criticism of the current supervisory system for creating conflicting objectives and thus confusing expectations for compliance. See Chapter 3, section D.3.

19 FinCEN comment request 58026.

20 Ibid. 58027.

${ }^{21}$ Ibid. 58028. Such a requirement would also help mitigate the conflict between the primary agencies' and LEAs' objectives. The latter's understanding of what constitutes an 'effective' compliance program may differ from FinCEN's.
} 
Both the AML Act and FinCEN comment request ${ }^{22}$ will take an extended period of time to be fully implemented.

\section{E Conclusion}

This book provides a unique framework that BSA and sanctions law practitioners can use in designing and implementing effective compliance and risk management systems. However, the task lies only partly in their hands. Such systems will not be capable of satisfying FinCEN's compliance expectations unless FIs' boards of directors and senior management allocate the resources necessary to bring their control infrastructure in line with the risks created by their business strategies. This book provides evidence of a 'compliance paradox' in BSA and sanctions regulation that creates significant hurdles for the design and execution of such a corporate strategy.

22 As an 'advanced notice of proposed rulemaking', the request is first seeking comments on a set of questions concerning a potential reform of AML/CFT regulation. The responses would then be used to propose specific rules for comment. Adoption of a final rule would be the last stage of rulemaking. 